\title{
Fellowship training in endourology: Impact on percutaneous nephrolithotomy access patterns
}

Jennifer Saluk, MD; Joshua Ebel, MD; Justin Rose, BS; Tasha Posid, MA, PhD; Michael Sourial, MD; Bodo Knudsen, MD

Department of Urology, The Ohio State University Wexner Medical Center, Columbus, OH, United States

Acknowledgements: The authors would like to acknowledge the contributions of departmental Clinical Research Coordinator, Alicia Scimeca, as well as Marilly Palettas, MPH, and Amy Lehman, MAS, for their statistical support on initial analyses. The authors did not receive support for this project; however, REDCap was provided by the authors' institution: The Ohio State University Center for Clinical and Translational Science grant support (National Center for Advancing Translational Sciences, Grant UL1TR002733).

Cite as: Saluk J, Ebel J, Rose J, et al. Fellowship training in endourology: Impact on percutaneous nephrolithotomy access patterns. Can Urol Assoc J 2021 September 24; Epub ahead of print. http://dx.doi.org/10.5489/cuaj.7339

Published online September 24, 2021

Corresponding author: Dr. Tasha Posid, Department of Urology, The Ohio State University Wexner Medical Center, Columbus, OH, United States; Tasha.Posid@osumc.edu

$* * *$

\section{Abstract}

Introduction: Percutaneous nephrolithotomy (PCNL) remains the treatment of choice for kidney stones larger than $2 \mathrm{~cm}$. Few studies have examined the reasons why some urologists obtain their own PCNL access while others prefer to have interventional radiology (IR) obtain access. The objective of this study was to investigate what factors influence this decision.

Methods: A survey was posted to the American Urological Association's (AUA) Young Urologist Community. Descriptive statistics and exploratory analyses were used to summarize practice trends and motivating factors.

Results: All 99 respondents began practicing within the past 11 years. Ninety-two currently perform PCNLs and $47 \%$ of them obtain their own access. Endourology fellowship-trained physicians were more likely to currently obtain their own access (75\%) compared to urologists who completed non-endourology fellowships ( $75 \%$ vs. $23 \%$, $\mathrm{p}=0.58)$ and non-fellowship-trained urologists ( $75 \%$ vs. $45 \%, p=0.01$ ). Logging $>50$ cases during training also predicted physicians obtaining their own access and having a larger annual number of PCNL cases. The most 
common motivator for obtaining one's own access was preference to control their own access point (95\%).

Conclusions: Urologist-obtained PCNL access was associated with greater training experience (endourology fellowship) and current annual PCNL case volume. Urologist-reported factors that influenced the decision to obtain one's own access include control of access, comfort level, and both physician and patient convenience. By identifying the factors that influence practice patterns, we may better address barriers, improve education to make urologist-obtained PCNL access feasible even without fellowship training, and ultimately improve outcomes and quality of care.

\section{Introduction}

The treatment of choice for kidney stones larger than two centimeters is percutaneous nephrolithotomy (PCNL). ${ }^{1}$ Access to the urinary tract for this procedure can be established by an interventional radiologist (IR) prior to or at the time of a PCNL or by the operating urologist at the start of the case with the use of fluoroscopy, ultrasound, endoscopy or a combination. There is a steep learning curve for PCNLs, which is primarily attributed to obtaining renal access. ${ }^{2}$ Currently, interventional radiologists obtain the majority of access during PCNL procedures. For example, one article found that from 2003-2015, only $17.0 \%$ of urologists in the United States obtained their own access, whereas the remaining access was obtained by interventional radiologists. ${ }^{3}$ Despite this tendency, urology-obtained access is noted to be a safe and effective single-stage procedure with lower complication rates, reduced length of stay, and decreased hospital costs when compared to IR-obtained access. ${ }^{3,4}$ Further, urologist-obtained access is associated with an increased stone-free rate. ${ }^{5}$

This brings up an interesting question: if urologist-obtained access results in positive patient outcomes, why do the majority of urologist rely of interventional radiologist to obtain access? In the current literature, few studies have investigated why some urologists obtain their own PCNL access and others do not. Bird et al. found that urologists trained to perform PCNLs during residency and those younger in age, regardless of number of years in practice, were more comfortable with the surgery. ${ }^{6}$ Further, fellowship trained urologists were more likely to obtain their own access than non-fellowship trained urologists. ${ }^{7}$ The primary objective of this study was to investigate practice trends among newly trained urologists, with a specific focus on PCNL access practices, training and motivation factors driving this decision. 


\section{Methods}

\section{Measurement}

A survey was created to gather demographic information, including years in practice, practice type, practice setting, PCNL exposure during residency, whether a fellowship was completed, whether they perform PCNLs, and annual PCNL case volume. Participants were also asked whether they previously and/or currently obtain their own access, technique used, and motivating factors for obtaining access. Survey questions were primarily formatted as forced-choice responses, with a few open-ended questions in which resopndents could type their answer in a text box. The survey was created via REDCap (Research Electronic Data Capture), a secure, web-based software platform designed to support data capture for research studies. ${ }^{8,9}$ REDCap was used for survey creation, distribution, and data storage. Informed consent was obtained via REDCap, prior to participants viewing the survey.

\section{Participants}

After obtaining approval from the local regulatory board, a representative from the American Urological Association (AUA) posted the survey link to the AUA's Young Urologist Community, an online forum composted of newly practicing urologists. The target demographic were young urologists who had completed residency or fellowship within approximately 13 years. The survey was active from October $20^{\text {th }}, 2018$, through November $14^{\text {th }}, 2018$. Survey participants could view an IRB-approved solicitation which identified the study as investigating obtaining PCNL access and motivating influence for this decision. No incentive was provided for participation in this study.

\section{Data analysis}

Demographic characteristics and survey responses were summarized using descriptive statistics. Comparisons for categorical variables, such as between urologist characteristics and PCNL practice patterns, were assessed using descriptive statistics, as well as Chi-square/Fisher's exact test, or two-sample t-test/Wilcoxon Rank Sum test for continuous variables, where appropriate. Logistic regression modeling was conducted to examine predictors for outcome variables of interest. Note that presented p-values were not adjusted for multiple comparisons. Statistical analysis was performed using SAS/STAT statistical software (version 9.4 of SAS for Windows, SAS Institute Inc., Cary, NC) and SPSS Statistics software (IBP SPSS Statistics for Windows, version 26.0. Armonk, NY: IBM Corp).

\section{Results}

\section{PCNL practices}

A total of 99 completed survey responses were included in the final analysis, none were excluded. Respondent demographic characteristics are summarized in Table 1. Respondents from 
every section of the AUA were represented in our survey responses. The median years of practice for respondents was 4 years (range: 0 - 11 years) and the most common response for practice type was 'Urology Group' (30\%). In addition, 40\% (39/99) of respondents reported completing a fellowship, with 51\% (20/39) of these in endourology.

The majority of urologists surveyed $(91 / 99,92 \%)$ reported that they currently perform PCNLs. Among these 91, 43/91 (47\%) reported that they currently obtain their own access. The majority of respondents reported obtaining their own access in $75-100 \%$ of cases $(37 / 43,86 \%)$. Those that obtain their own access primarily do so by fluoroscopic guidance $(37 / 43,86 \%)$, as compared to endo-guided or retrograde (4/43, 9\%), combined fluoroscopic and endo-guided $(2 / 43,5 \%)$, and ultrasound $(0 / 43,0 \%)$. Motivating factors behind obtaining one's own access are summarized in Table 2 . The primary motive was "I prefer to control my own access" (35/43, $92 \%$ ), whereas, in contrast, the most common reasons for not obtaining one's own access were "it is more convenient to have IR place nephrostomy tube" $(21 / 48,44 \%)$ and "I do not feel comfortable obtaining access" (20/48, 42\%).

\section{Predictors for obtaining PCNL access}

Two logistic regression models were run examining predictors to obtaining PCNL access onself and predictors of amount of PCNLs currently performed. Years of practice, practice type, practice setting, number of PCNLs performed annually, whether they obtained PCNL access when they started, PCNL training, fellowship status (none, non-endourology, endourology) were entered as independent variables. Whether or not urologists currently obtained their own PCNL access was significantly predicted by number of PCNL cases performed annually $(\mathrm{p}=0.021)$, whether they obtained PCNL access when they went into practice $(p<0.001)$, and fellowship status ( $p=0.042$ ). The proportion of cases that urologists obtained their own access for was significantly predicted by whether they obtained access when they first started practice $(\mathrm{p}=0.073$, marginal) and PCNL training ( $\mathrm{p}=0.03$ ). See Figures 1-3.

Post-hoc analyses indicated that those who completed an endourology fellowship performed more PCNLs than either those who completed a non-endourology fellowship $(p=0.007)$ or those who did not complete any fellowship ( $p=0.023)$, likely accounting for the significantly greater of urologists obtaining - and then continuing to obtain - their own access as they started their careers. Overall, fellowship completion between the two groups was similar [urologist-obtained: 42\% (18/43) vs. IR-obtained: 35\% (17/48); $\mathrm{p}=0.666$ ]. However, endourology fellowship-trained physicians were more likely to currently obtain their own access compared those with no fellowship training and those who completed non-endourology fellowships [15/20 (75\%) vs. $25 / 56(45 \%)$ vs. $4 / 15(27 \%) ; p=0.01, p=0.058]$. A higher proportion of physicians who currently obtain their own access logged greater than fifty cases during training where they obtained their own access [37\% (16/43) vs. 8\% who do not currently obtain their own access $(4 / 48) ; \mathrm{p}<0.001]$. The urologists currently obtaining their own access 
also reported a larger annual PCNL case volume (21-50 cases per year) [37\% (16/43) vs. 8\% (4/48) who do not currently obtain their own access; $p<0.001]$.

\section{Discussion}

Numerous studies have shown that urologist-obtained PCNL access is safe, effective, and has similar or decreased complication rates compared to IR-placed access. ${ }^{3,4,10,11}$ Despite favorable outcome data regarding urologist-obtained access, ${ }^{5}$ the rates of urologist-obtained access remain low (47\%). In our study, the most common reasons for not obtaining one's own access were physician convenience (44\%) and lack of comfort (42\%).

Between those who do and do not perform PCNLs, we found no strong association in the number of PCNLs logged during training with urologist-obtained access. However, respondents who currently perform PCNLs were more likely to obtain their own access if they performed more PCNLs in training where access was urologist-obtained and if they currently have a higher PCNL case volume. Endourology fellowship trained urologists were also more likely to obtain their own access compared to non-fellowship trained urologist. Thus, while the choice of whether or not to include PCNLs in one's practice scope did not seem reliant on training case volume, physicians were more likely to obtain their own access if they had additional training experience obtaining access and if they perform the procedure regularly. This is in-line with the fact that PCNL access is the most challenging step, and increased training and experience likely lead to increased comfort level. The additional experience afforded by an endourology fellowship only adds to this, more easily advancing urologists past the learning curve threshold to the point where they feel comfortable obtaining PCNL access in practice. To this point, the authors note that fellowship training does not necessarily include or encompass percutaneous access training, even in endourology.

It was also noteworthy to find that none of urologists obtaining access in this survey did so with ultrasound, which we known to be a safe, and some would argue superior method. Ultrasound has the benefit of no radiation exposure and real-time anatomy identification, while offering comparable stone-free rates, complications, time and success rate of access. ${ }^{12}$ Fluoroscopic guided access however remains the dominant technique at the time of this survey, which is likely a reflection of training experience and comfort level. We would anticipate an increase in ultrasound guided access in the future, but this highlights that fluoroscopic guided access is still the most common employed technique by urologists to gain access.

Thus, one potential strategy for improvig urologist-obtained PCNL access and potentially ultrasound-guided access, is to improve PCNL-access experience during training and practice through simulation. Urologists may not have the ability to change overall PCNL case volume seen during residency or in practice. However, supplemental education and skills refreshers through hands-on simulation may improve residents' and practicing urologists' overall experience and confidence with obtaining access at an early stage in their career without 
requiring them to complete an endourology fellowship. Simulation training has been successfully used to help train medical students and residents in common procedures such as central lines and intubation for years. ${ }^{13,14}$ Virtual and tactile simulation-based training has been increasingly utilized for procedures requiring specialized skills, with 29 papers on PCNL simulation alone published between 2000 and 2015. ${ }^{15,16}$ By supplementing education or case volume, PCNL access simulations may push some urologists over the experience and comfort thresholds necessary to make them feel comfortable obtaining their own PCNL access in practice or potentially to move to a different method of access, such as ultrasound-guided. Based on our current findings, the authors that there may be a role for simulation training as practice for obtaining one's own access. Although we did not look at this explicitly via the survey in the current study, this is something to consider.

There were several limitations to our study. The small sample size and low response rate greatly limit the statistical yield of our study. However, survey studies of this nature involving medical trainees have typically yielded low response rates, ${ }^{17}$ as do studies in which incentives are not offered ${ }^{18}$ and when recruitment is conducted via a listserv ${ }^{19}$ (similar to that of the forum used). Due to the nature of our questions and their branching logic, some questions yielded a small number of respondents, thus limiting our ability to detect any potential differences among certain subgroups. As this survey was posted to a large forum, it is unknown who specifically viewed the link and if this sample is representative of newly-practicing urologists in the nation. However, as noted, demographics indicate a diverse range across sections and a wide demographic of practice types. The reported respondent fellowship rate, and more specifically endourology fellowship rate, were quite high, which hints to possible sampling bias and resultant skewing of data towards those with more endourology-heavy practice trends. Survey studies may also be impacted by recall bias, as we ask respondents about yearly PCNL case volume, percentage of cases they obtain their own access, and PCNL volume during residency. Finally, due to the categorical structure and forced-response structure of most of our survey questions, and the fact that conclusions are based on a survey method in and of itself, possible responses may have been limited. Nevertheless, this study provides unique information on practice trends and attitudes of new urologists entering the workforce, which may offer insight into potential areas to improve both resident education and patient care.

\section{Conclusions}

Our findings suggest that urologist-obtained PCNL access was associated with training experience, completion of an endourology fellowship, and current annual PCNL case volume. Urologist reported factors that influenced the decision to obtain one's own access include control of access, comfort level, and both physician and patient convenience. By identifying these trends and attitudes, we may not only better understand the logistical considerations in practice, but also address technical areas that may benefit from supplemental education. While it is not feasible for 
all urologists to complete an endourology fellowship, simulation education during training or in practice may help to sharpen skills and provide additional experience necessary for urologist to feel comfortable performing their own PCNL access.

Conflicts of interest: Dr. Knudsen is a consult for Bard, Boston Scientific, and Olympus.

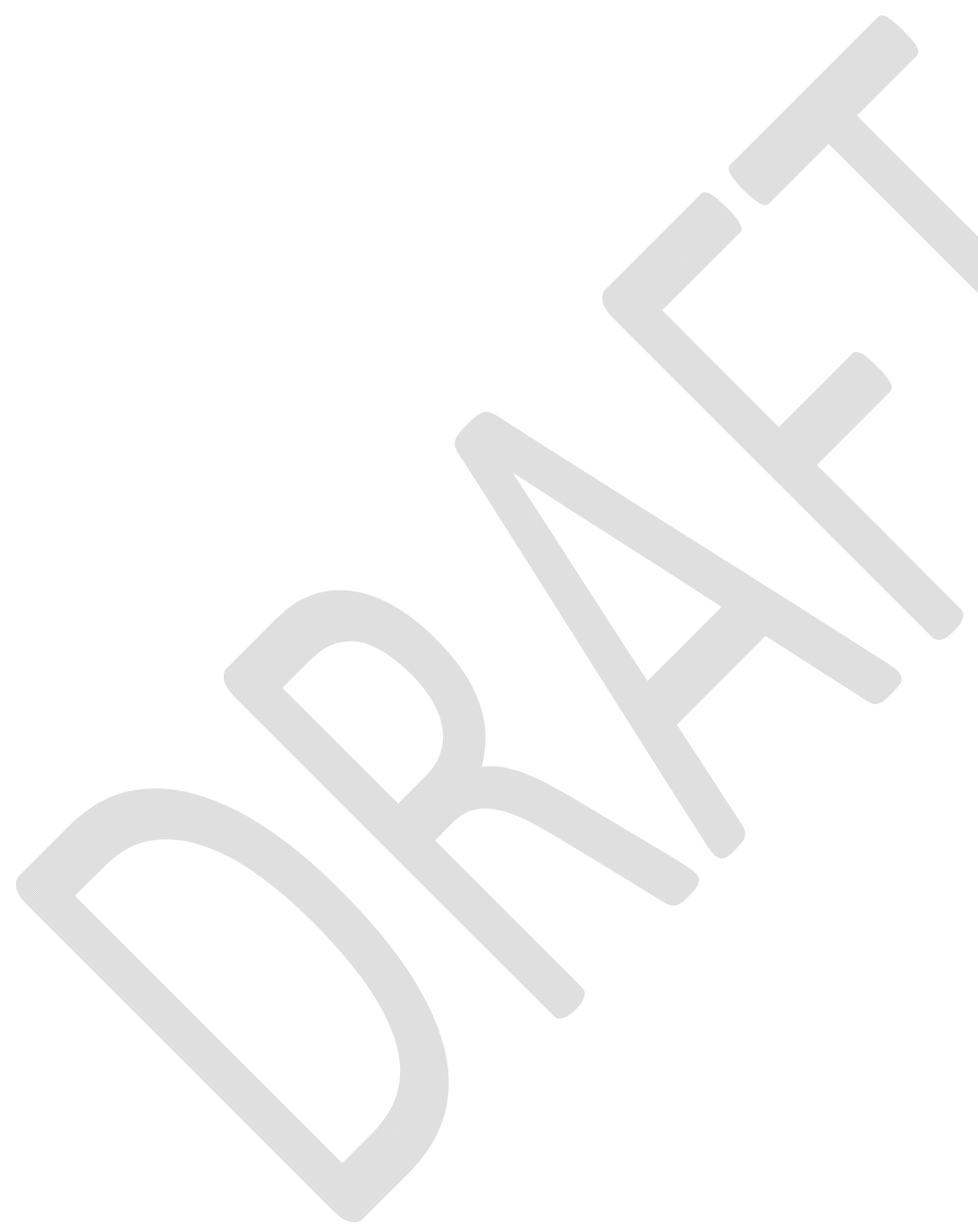




\section{References}

1. Assimos D, Krambeck A, Miller NL, et al. Surgical management of stones: American Urological Association/Endourological Society Guideline, PART II. J Urol 2016 Oct;196:1161-9.

2. de la Rosette JJ, Laguna MP, Rassweiler JJ, et al. Training in percutaneous nephrolithotomy--a critical review. Eur Urol 2008 Nov;54:994-1001.

3. Speed, J. M., Wang, Y., Leow, J. J., et al. (2017). The effect of physician specialty obtaining access for percutaneous nephrolithotomy on perioperative costs and outcomes. J Endourol. 2017 Nov;31:1152-6.

4. El-Assmy, A. M., Shokeir, A. A., Mohsen, T., et al. (2007). Renal access by urologist or radiologist for percutaneous nephrolithotomy-Is it still an issue? J Urol $2007 \mathrm{Sep}$; 178(3 Pt 1):916-20.

5. Tomaszewski, J. J., Ortiz, T. D., Gayed, B. A., et al. (2010). Renal access by urologist or radiologist during percutaneous nephrolithotomy. J Endourol 2010 Nov;24:1733-7.

6. Bird, V. G., Fallon, B., \& Winfield, H. N. (2003). Practice patterns in the treatment of large renal stones. J Endourol 2003 Aug;17:355-63.

7. Sivalingam, S., Cannon, S. T., \& Nakada, S. Y. (2014). Current practices in percutaneous nephrolithotomy among endourologists. J Endourol 2014 May;28:524-7.

8. Harris PA, Taylor R, Thielke R, et al. Research electronic data capture (REDCap)--a metadata-driven methodology and workflow process for providing translational research informatics support. J Biomed Inform 2009;42:377-81.

9. Harris PA, Taylor R, Minor BL, et al. The REDCap consortium: Building an international community of software platform partners. J Biomed Inform 2019;95:103208.

10. Jayram G, Matlaga BR. Contemporary practice patterns associated with percutaneous nephrolithotomy among certifying urologists. J Endourol 2014 Nov;28:1304-7.

11. Watterson JD, Soon S, Jana K. Access related complications during percutaneous nephrolithotomy: urology versus radiology at a single academic institution. J Urol 2006 Jul;176:142-5.

12. Yang YH, Wen YC, Chen KC, Chen C. Ultrasound-guided versus fluoroscopy-guided percutaneous nephrolithotomy: a systematic review and meta-analysis. World J Urol 2019;37:777-88.

13. Fernandez, G.L., Page, D.W., Coe, N.P. et al. Boot camp: educational outcomes after 4 successive years of preparatory simulation-based training at the onset of internship. $J$ Surg Educ 2012; 69: 2.

14. Thompson, L., Exline, M., Leung, C.G. et al. A clinical procedures curriculum for undergraduate medical students: the eight-year history of a third-year immersive experience. Med Educ Online 2016; 21: 29486.

15. Knudsen BE, Matsumoto ED, Chew $\mathrm{BH}$, et al. A randomized, controlled, prospective study validating the acquisition of percutaneous renal collecting system access skills using a computer based hybrid virtual reality surgical simulator: phase I. J Urol 2006 Nov; $176: 2173-8$ 
16. Pietropaolo A, Proietti S, Geraghty R, et al. Trends of 'urolithiasis: interventions, simulation, and laser technology' over the last 16 years (2000-2015) as published in the literature (PubMed): a systematic review from European section of Uro-technology (ESUT). World J Urol 2017 Nov;35:1651-1658.

17. Hughes JDM, Azzi E, Rose GW, et al. A survey of senior medical students' attitudes and awareness toward teaching and participation in a formal clinical teaching elective: A Canadian perspective. Med Educ Online; 22. Epub ahead of print 2017. DOI: 10.1080/10872981.2016.1270022.

18. Kellerman SE, Herold J. Physician response to surveys. Am J Prev Med 2001; 20: 61-7.

19. Saleh A, Bista K. Examining Factors Impacting Online Survey Response Rates in Educational Research: Perceptions of Graduate Students. J Multidiscip Eval 2017; 13: 63-74.

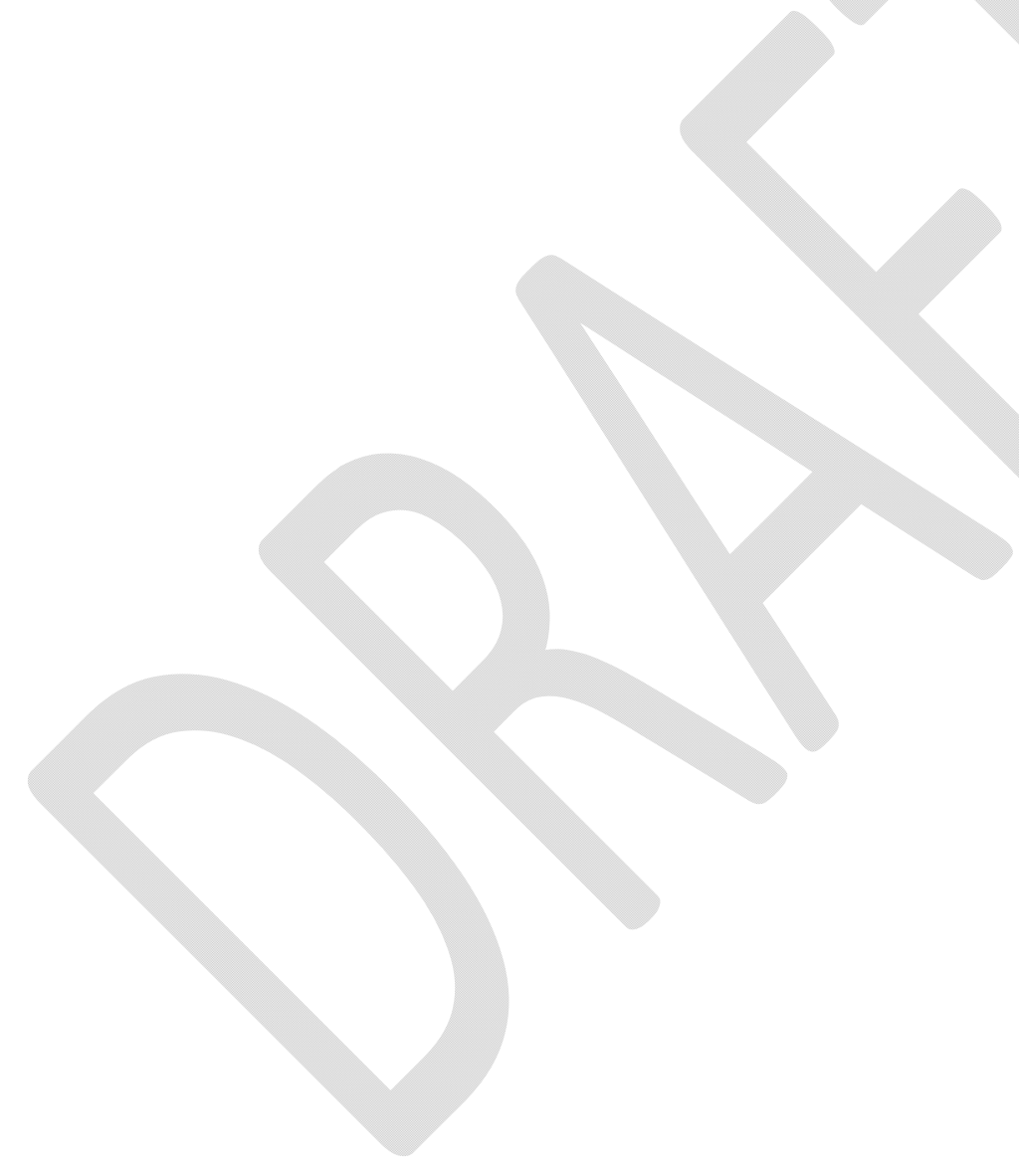




\section{Figures and Tables}

Fig. 1. Fellowships completed among those who perform percutaneous nephrolithotomies (PCNLs). Data is stratified by whether or not survey respondents currently obtain their own PCNL access. IR: interventional radiologist.

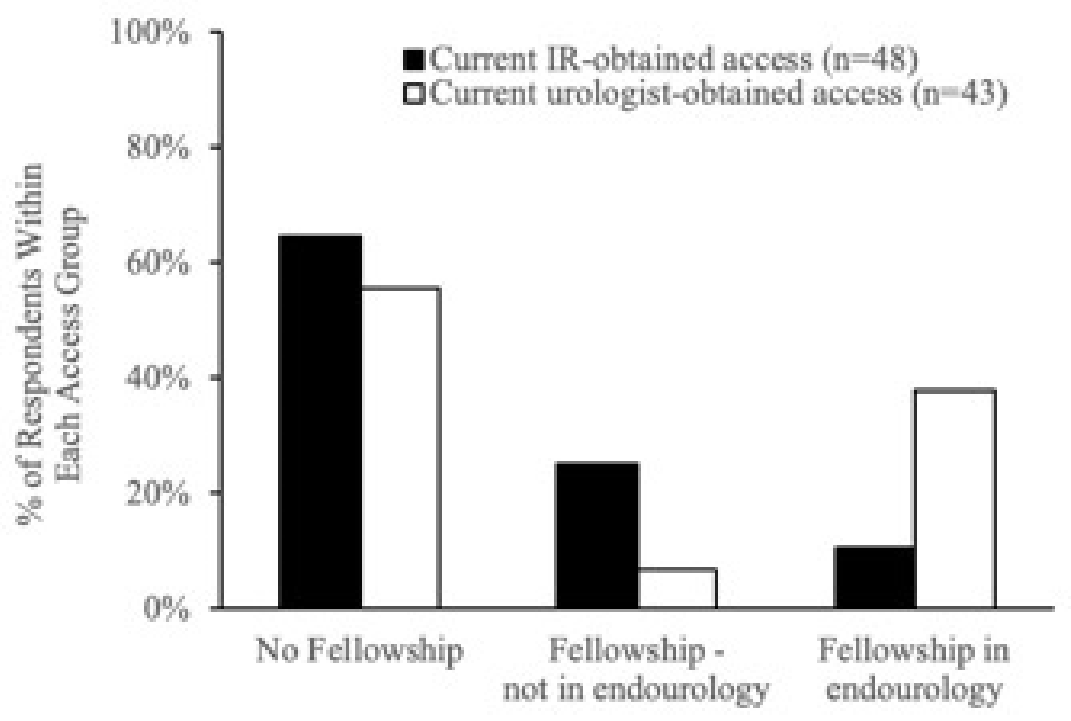

Fig. 2. Number of percutaneous nephrolithotomies (PCNLs) logged during training physicianobtained access. Data is stratified by whether or not survey respondents currently obtain their own PCNL access. IR: interventional radiologist.

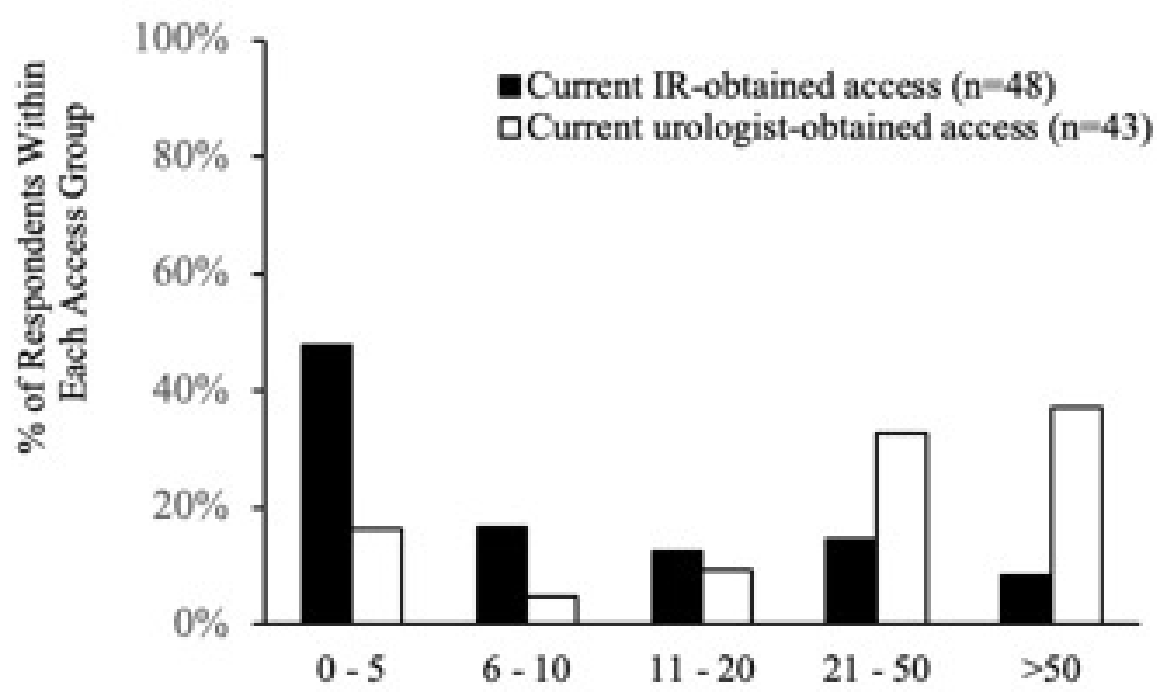


Fig. 3. Current number of percutaneous nephrolithotomies (PCNLs) performed per year, broken down by whether or not PCNL access was urologists-obtained. IR: interventional radiologist.

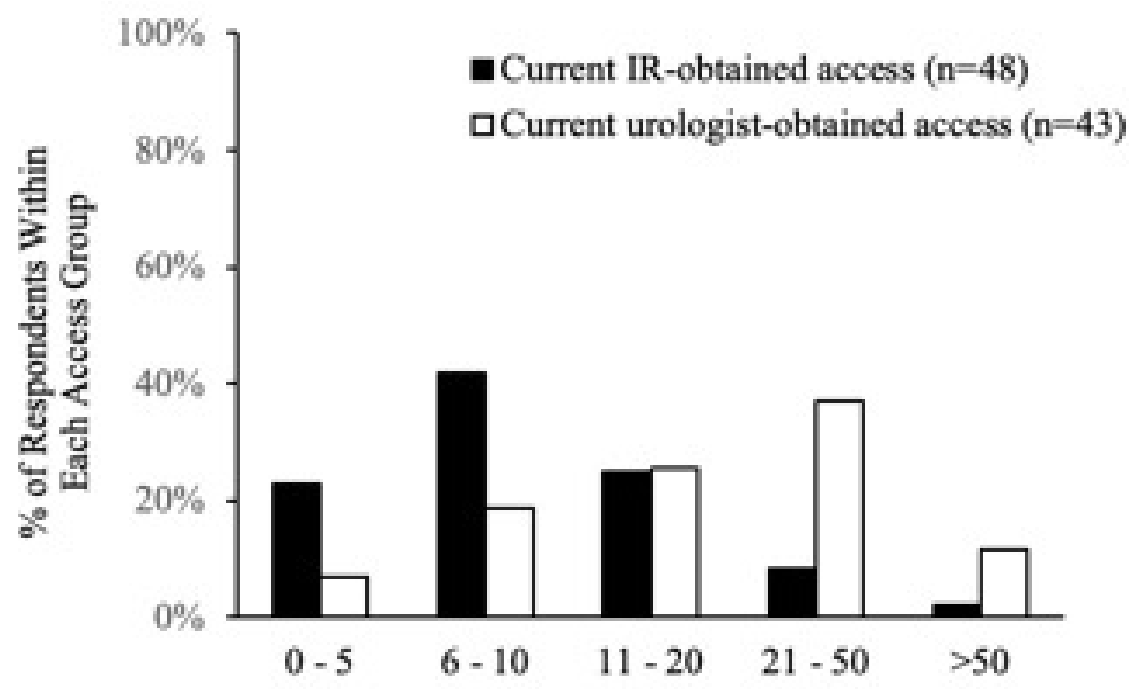




\begin{tabular}{|c|c|c|}
\hline Survey question & Response & $\begin{array}{c}\text { Total } \\
(\mathbf{n}=99)\end{array}$ \\
\hline $\begin{array}{l}\text { How many years ago did you begin your } \\
\text { practice? }\end{array}$ & $\begin{array}{l}\text { Median }[\mathrm{IQR}] \\
\quad(\min , \max )\end{array}$ & $\begin{array}{c}\operatorname{missing}=2 \\
4[2,6] \\
(0,11)\end{array}$ \\
\hline $\begin{array}{l}\text { Which best describes your practice } \\
\text { type? }\end{array}$ & $\begin{array}{c}\text { Full-time academic } \\
\text { Full-time managed care } \\
\text { Hospital } \\
\text { Multispecialty group } \\
\text { Solo practice } \\
\text { Urology group } \\
\text { VA/military } \\
\text { Other (please specify) }\end{array}$ & $\begin{aligned} & 23(23 \%) \\
& 2(2 \%) \\
& 17(17 \%) \\
& 15(15 \%) \\
& 4(4 \%) \\
& 30(30 \%) \\
& 7(7 \%) \\
& 1(1 \%) \\
&\end{aligned}$ \\
\hline $\begin{array}{l}\text { In what setting do you practice? (Please } \\
\text { select answer that best applies) }\end{array}$ & $\begin{array}{l}\text { Large academic hospital } \\
\text { Large private hospital } \\
\text { Mid-size community practice } \\
\text { Rural community }\end{array}$ & $\begin{array}{l}23(23 \%) \\
24(24 \%) \\
42(42 \%) \\
10(10 \%)\end{array}$ \\
\hline In what AUA section do you practice? & $\begin{array}{c}\text { Mid-Atlantic } \\
\text { New England } \\
\text { New York } \\
\text { North Central } \\
\text { Northeastern } \\
\text { South Central } \\
\text { Southeastern } \\
\text { Western }\end{array}$ & $\begin{aligned} & 8(8 \%) \\
& 8(8 \%) \\
& 2(2 \%) \\
& 22(22 \%) \\
& 2(2 \%) \\
& 19(19 \%) \\
& 22(22 \%) \\
& 16(16 \%)\end{aligned}$ \\
\hline $\begin{array}{l}\text { Please estimate the total number of } \\
\text { PCNL cases you logged during training } \\
\text { where you obtained your own access: }\end{array}$ & $\begin{array}{c}0-5 \\
6-10 \\
11-20 \\
21-50 \\
>50\end{array}$ & $\begin{array}{l}35(35 \%) \\
11(11 \%) \\
10(10 \%) \\
22(22 \%) \\
21(21 \%)\end{array}$ \\
\hline Did you complete a fellowship? & $\begin{array}{l}\text { No } \\
\text { Yes }\end{array}$ & $\begin{array}{l}60(61 \%) \\
39(39 \%)\end{array}$ \\
\hline Was your fellowship in endourology? & $\begin{array}{l}\text { No } \\
\text { Yes }\end{array}$ & $\begin{array}{l}19(49 \%) \\
20(51 \%)\end{array}$ \\
\hline Do you currently perform PCNLs? & $\begin{array}{l}\text { No } \\
\text { Yes }\end{array}$ & $\begin{array}{c}8(8 \%) \\
91(92 \%)\end{array}$ \\
\hline $\begin{array}{l}\text { How many PCNLs do you perform per } \\
\text { year? }\end{array}$ & $\begin{array}{c}0-5 \\
6-10 \\
11-20 \\
21-50 \\
>50\end{array}$ & $\begin{array}{c}14(15 \%) \\
28(31 \%) \\
23(25 \%) \\
20(22 \%) \\
6(7 \%)\end{array}$ \\
\hline
\end{tabular}




\begin{tabular}{l|c|c|}
\begin{tabular}{l|c} 
Do you currently obtain your own \\
access? \\
(n=91 who perform PCNLs)
\end{tabular} & No & $48(55)$ \\
& Yes & \\
\hline
\end{tabular}

AUA: American Urological Association; IQR: interquartile range; PCNL: percutaneous nephrolithotomy.

\begin{tabular}{|c|c|c|}
\hline Survey question & Response & n $(\%)$ \\
\hline $\begin{array}{l}\text { Why do you currently obtain } \\
\text { your own access? } \\
\text { ( } n=43 \text { who obtain their own } \\
\text { access) }\end{array}$ & $\begin{array}{l}\text { I prefer to control my own access } \\
\text { IR is not available } \\
\text { Patient convenience } \\
\text { Cost savings } \\
\text { [missing] }\end{array}$ & $\begin{array}{l}35(81 \%) \\
1(2.3 \%) \\
1(2.3 \%) \\
1(2.3 \%) \\
5(12 \%)\end{array}$ \\
\hline $\begin{array}{l}\text { Why do you currently NOT } \\
\text { obtain your own access? } \\
\text { ( } \mathrm{n}=48 \text { who do not obtain their } \\
\text { own access) }\end{array}$ & $\begin{array}{c}\text { It is more convenient to have IR place nephrostomy tube } \\
\text { I do not feel comfortable obtaining access } \\
\text { I think access takes too long } \\
\text { Concern for complications while obtaining access } \\
\text { My patients often already have a nephrostomy tube in } \\
\text { place } \\
\text { I have limited OR time }\end{array}$ & $\begin{array}{l}21(44 \%) \\
20(42 \%) \\
3(6 \%) \\
2(4 \%) \\
1(2 \%) \\
1(2 \%)\end{array}$ \\
\hline $\begin{array}{l}\text { [If you have switched from IR- } \\
\text { obtained to urologist-obtained } \\
\text { access,] why? }\end{array}$ & $\begin{array}{l}\text { Patient convenience } \\
\text { Negative experience with IR-obtained access } \\
\text { I prefer to control my own access point } \\
\text { Wanted to develop my practice before starting to obtain my } \\
\text { own access }\end{array}$ & $\begin{array}{l}2(40 \%) \\
1(20 \%) \\
1(20 \%) \\
1(20 \%)\end{array}$ \\
\hline $\begin{array}{l}\text { [If you have switched from } \\
\text { urologist-obtained to IR- } \\
\text { obtained access,] why? }\end{array}$ & $\begin{array}{c}\text { It is more convenient to have IR place NT } \\
\text { I have limited OR time }\end{array}$ & $\begin{array}{l}3(75 \%) \\
1(25 \%)\end{array}$ \\
\hline $\begin{array}{l}\text { Why do you not currently } \\
\text { perform PCNLs? } \\
\text { (n=8 who do not currently } \\
\text { perform PCNLs) }\end{array}$ & $\begin{array}{c}\text { I prefer to refer these patients to a specialist } \\
\text { Concern for complications } \\
\text { Hospital limitations (equipment or IR not available) } \\
\text { I do not treat kidney stones }\end{array}$ & $\begin{array}{c}4(50 \%) \\
2(25 \%) \\
1(12.5 \%) \\
1(12.5 \%)\end{array}$ \\
\hline
\end{tabular}

IR: interventional radiologist; OR: operating room; PCNL: percutaneous nephrolithotomy. 